\title{
Effect of mechanical attrition on microstructure and property of electroplating of copper plating in acid solution
}

\author{
Changjie Feng, Namei Wu, Shuilian Hu \\ School of Materials Science and Engineering, Nanchang Hangkong University, Nanchang, \\ 330063, China
}

Keywords: Mechanical attrition, Acid copper electroplating, Anti-carburizing

\begin{abstract}
In this paper, the mechanical attrition(MA) was supplied in a traditional electroplating process by rolling movement of different diameter of glass balls in the acid copper plating electrolyte to study the effects of different diameters of the glass balls on microstructure of copper plating and the properties of carbon-impervious, grain refine and corrosion resistance. The results showed that the grain size of the plating had obviously decreased in the MA process, and with increasing the diameters of the glass balls, the porosity, corrosion resistance and the properties of carbon-impervious of the plating were first increased and then decreased.
\end{abstract}

\section{Introduction}

Acid copper electroplating with sulfate extensive applied in industrial production bath has a history of more than a century due to its simple composition, stable and cheap electroplating solution and so on[1]. It is known that copper plating has been used as anti-carburizing plating because the copper layer has a high contact and the carbon has the features that don't form solid solution or compound with copper. However, the thick $\mathrm{Cu}$ plating is required to be used as anti-carburizing on account of the coarse grain of the $\mathrm{Cu}$ plating.

Surface mechanical attrition treatment(SMAT) is an approach to improving comprehensive performance of materials rely on more strong plastic deformation in the metal surface, which can lead materials with nanoscale, submicron and micro of grain size by high frequency and direction of the load[2,3]. The SMAT has the advantages of wide range of application, high toughness, good interface bonding and so on. Based on the deficiencies of traditional electroplated(TEP) copper plating, the SMAT was applied in acidic copper plating by using mechanical attribution to enhance the corrosion resistance and anti-carburizing of the copper plating.

\section{Experimental methods}

The A3 steel samples with dimensions of $20 \mathrm{~mm} \times 40 \mathrm{~mm} \times 1 \mathrm{~mm}$ mounted in epoxy resin as cathode. Before plating copper, the A3 steel was electroplated with Ni. Electroplating experiments were carried out with current density of $5 \mathrm{~A} / \mathrm{dm} 2$ in the traditional sulfate electroplating solution (190g/L CuSO4.5H2O and 60g/L H2SO4) at room temperature for 30min. Glass balls, covered about $1 / 4$ surface area of each sample, with diameters of $4 \mathrm{~mm}, 6 \mathrm{~mm}, 8 \mathrm{~mm}$ and $10 \mathrm{~mm}$ were used respectively on the cathode surface to provide mechanical impact. A plastic tank filled with plating solution was placed on the top of a vibrator[4], when the vibrator moved vertically with an amplitude of $1 \mathrm{~mm}$, the plastic tank swinged around the bearing with $15^{\circ}$. The microstructures of the copper platings plated by MA electroplating at different diameters of glass balls were examined by using scanning electron microscopy(SEM). Stick filter paper method was used to measure the porosity by observing the number of blue dot in each square centimeter. To evaluate the corrosion resistance of the plated copper platings, polarization curves were measured in a three-electrode cell by using a galvano-chemistry Workstation(CHI-660C) in $3.5 \% \mathrm{NaCl}$ solution at room temperature with a sweep rate of $0.5 \mathrm{mV} / \mathrm{s}$. The composition was $15 \mathrm{wt} \% \mathrm{BaCO}$, 3wt $\% \mathrm{CaCO}$, 88wt $\%$ charcoal power. The paraments were bured at $820 \mathrm{C}$ for $30 \mathrm{~min}$, heated to $900 \mathrm{C}$ for $90 \mathrm{~min}$, then cooled at $850 \mathrm{C}$ for $30 \mathrm{~min}$ and finally quenched. The cross-sectional microhardness of the carburized steel was measured by a digital microhardness tester(HVS-1000) with a load of $0.1 \mathrm{~N}$ for 
20s.

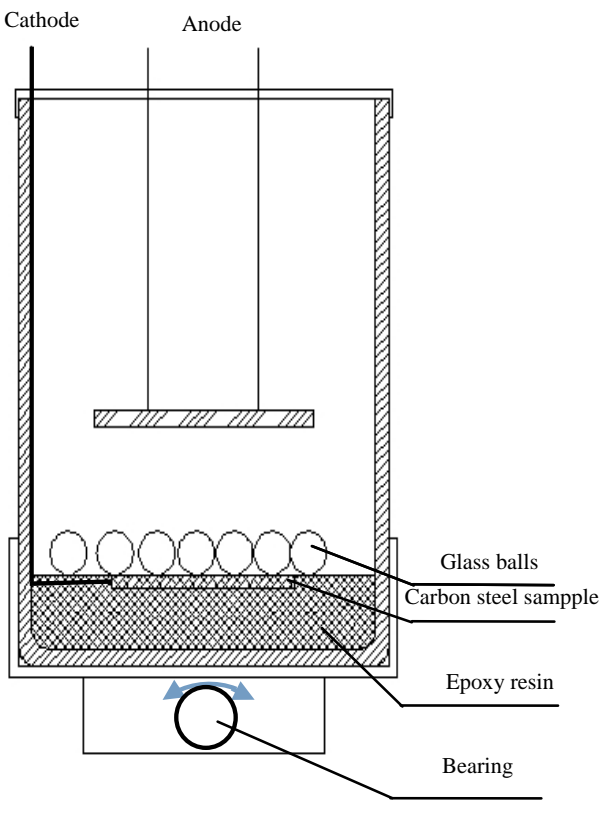

(a)

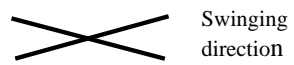

(b)

Fig.1 Schematic diagram of mechanical assisted electroplating device and swinging direction (a) MA electroplating device, (b) swinging direction.

\section{Results}

\section{Surface morphology}

Fig. 2 presents the surface morphology of copper platings electroplated with different diameter of glass balls. Fig.2(a) shows the surface of copper plating after TEP is rough and uneven. It can be seen that many pyramid-like crystals with size of 1-6 $\mu \mathrm{m}$ form nonuniformly on the surface of copper plating after TEP and coarse grain were surrounded by fine grains. While, from Fig.2(b)-(d), it can be seen that the grain size increase with increasing diameter of glass ball and distribute uniformly on the surface. Compared with copper plating after TEP, the grain on the surface of copper plating with MA process is finer than that of copper plating with TEP. As shown in Fig. 2(e) and (f), it is clear to see there are a little "cauliflower-like" grains with a diameter of $6 \mu \mathrm{m}$ surrounded by small grains with a diameter less than $1 \mu \mathrm{m}$ when the glass balls with diameter of 10 $\mathrm{mm}$ are used.With MA process, the rolling glass balls enhance convection and limiting current density. However glass balls change the direction of power line while current density of actual area is bigger than the setting current density. It was clear to see that the "cauliflower-like" grains were detected on the surface of copper plating when the glass balls with diameter of $10 \mathrm{~mm}$ are used. This would explain when the glass ball with diameter of $10 \mathrm{~mm}$ was used in the electroplating process, the actual current density is bigger than the limiting current density. 


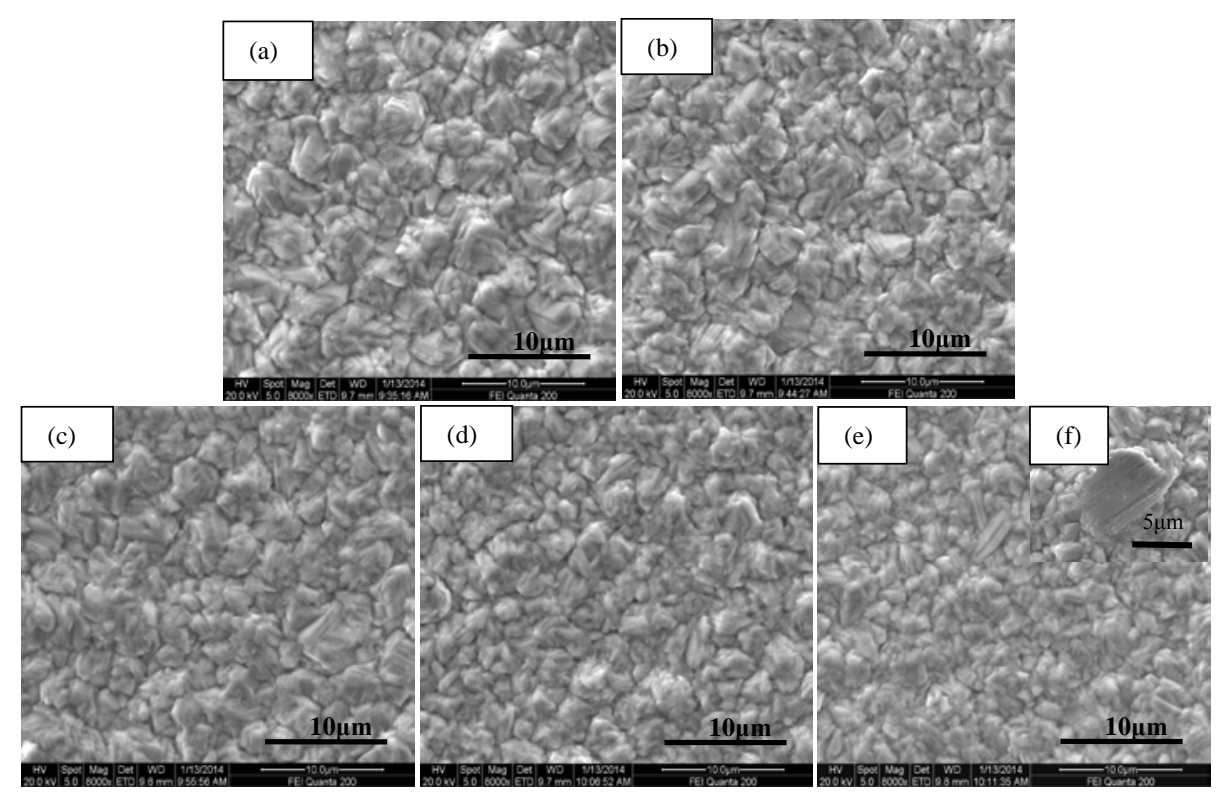

Fig.2 Surface morphologies of copper plating by mechanical attrition electroplating process at different diameter of glass ball: (a) TEP; (b) 4mm; (c) 6mm; (d) 8mm; (e) 10mm; (f) local coarse

\section{Macroscopic performance} grains with diameter of $10 \mathrm{~mm}$.

\section{Porosity}

Fig.3 shows the porosity of copper plating after TEP and with MA process. It is know that the porosity of copper plating after TEP is 1.25 per $\mathrm{cm} 2$. With MA process, the porosity of copper plating is lesser than that of copper plating after TEP. Therefore, MA action can affect the electroplating process and the porosity of plating. According to Fig.3, it can be seen that the porosity of copper plating decrease as the diameter of glass balls increases from $0 \mathrm{~mm}$ to $8 \mathrm{~mm}$. When the diameter of glass balls is $8 \mathrm{~mm}$, the porosity of plating is least. However, when the glass balls with the diameter of $10 \mathrm{~mm}$, the porosity of plating is bigger than that of $8 \mathrm{~mm}$. So, the best effect of MA action on the porosity of copper plating is glass balls with diameter of $8 \mathrm{~mm}$.

Table.3 Porosity of copper plating by mechanical attrition electroplating process at different diameter of glass ball

\begin{tabular}{llllll}
\hline $\begin{array}{l}\text { Diameter of } \\
\text { glass ball (mm) }\end{array}$ & 0 & 4 & 6 & 8 & 10 \\
\hline $\begin{array}{l}\text { Porosity(per } \\
\begin{array}{l}\text { square } \\
\text { centimetre) }\end{array}\end{array}$ & 1.25 & 0.9 & 0.85 & 0.5 & 0.75 \\
\hline
\end{tabular}

\section{Corrosion resistance}

Fig. 4 shows the polarization curves of carbon steel and mechanically assisted electroplated and TEP copper platings in $3.5 \% \mathrm{NaCl}$ solution at room temperature. According to polarization curves, the Ecorr and Icorr of copper plating are obtain, as shown in Table. 2. The Ecorr illustrates corrosion tendency of plating, and the Icorr shows rate of corrosion. According to Fig.4, it was clear to seen that during electroplating process MA action can lead to enhance the Ecorr of copper plating and decrease the Icorr of copper plating. Zhaoxia Ping[5,6]etc found similar law by studying mechanically assisted electroplating of Ni-P plating on carbon steel. Polarization curves reveal that the Icorr of copper plating first decrease and then increase as the diameter of glass balls increase, and Icorr is smallest when the diameter is $8 \mathrm{~mm}$, as shown in Table.2. Therefore, MA action can be effectively refined grains, decreased porosity and enhanced corrosion resistance of copper plating. 


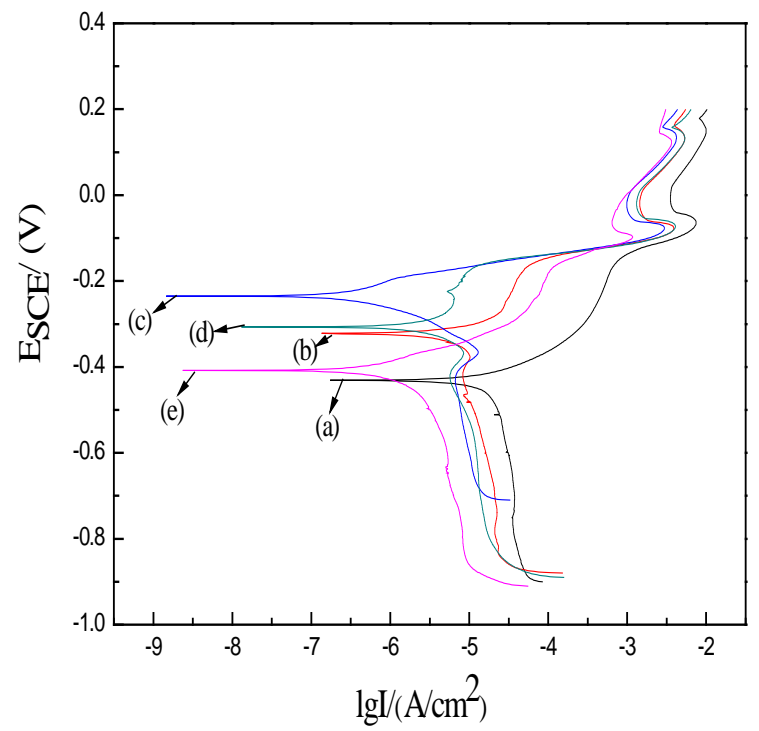

Fig.4 Polarization curves of copper plating by mechanical attrition electroplating process at different diameter of glass ball in 3.5\% NaCl solution: (a) TEP; (b) 4mm; (c) 6mm; (d) 8mm; (e) $10 \mathrm{~mm}$.

Table 2 Fitting result of polarization curves in the $3.5 \% \mathrm{NaCl}$ solution at room temperature

\begin{tabular}{llll}
\hline \multirow{2}{*}{ sample } & $\begin{array}{l}\text { Diameter of glass } \\
\text { ball(mm) }\end{array}$ & Ecorr/V & $\mathrm{I}_{\text {corr }} /\left(\mathrm{A} / \mathrm{cm}^{2}\right.$ \\
\hline TEP & 0 & -0.602 & $2.104 \times \mathrm{E}-5$ \\
MA electroplating & 4 & -0.357 & $3.802 \times \mathrm{E}-6$ \\
MA electroplating & 6 & -0.228 & $2.003 \times \mathrm{E}-6$ \\
MA electroplating & 8 & -0.255 & $1.323 \times \mathrm{E}-6$ \\
MA electroplating & 10 & -0.517 & $2.48 \times \mathrm{E}-6$ \\
\hline
\end{tabular}

\section{The property of anti-carburizing}

As the carbon content in the carbon steel increases so does the hardness of carbon steel increase. Therefore, the change in cross-section hardness of carbon steel before and after carburizing evaluate the property of carbon-impervious. Fig.5 shows microhardness of cross-section substract after carburizing under copper coating by mechanical attrition electroplating process at different diameter of glass ball. It was clear to see that the case depth of carbon steel without copper plating is $350 \mu \mathrm{m}$ by carburizing. Fig.5(b) is the part of dotted line in the Fig. 5(a). As shown in Fig.5(b), the case depth of carbon steel with TEP is $54 \mu \mathrm{m}$, and with MA process that of carbon steel decrease. It revealed that the case depth decrease with the diameter of glass ball from $4 \mathrm{~mm}$ to $8 \mathrm{~mm}$, when the diameter of glass ball is $10 \mathrm{~mm}$, the case depth increase. So, the property of carbon-impervious of copper plating is best one with diameter of $8 \mathrm{~mm}$, and the case depth is $14 \mu \mathrm{m}$. . 


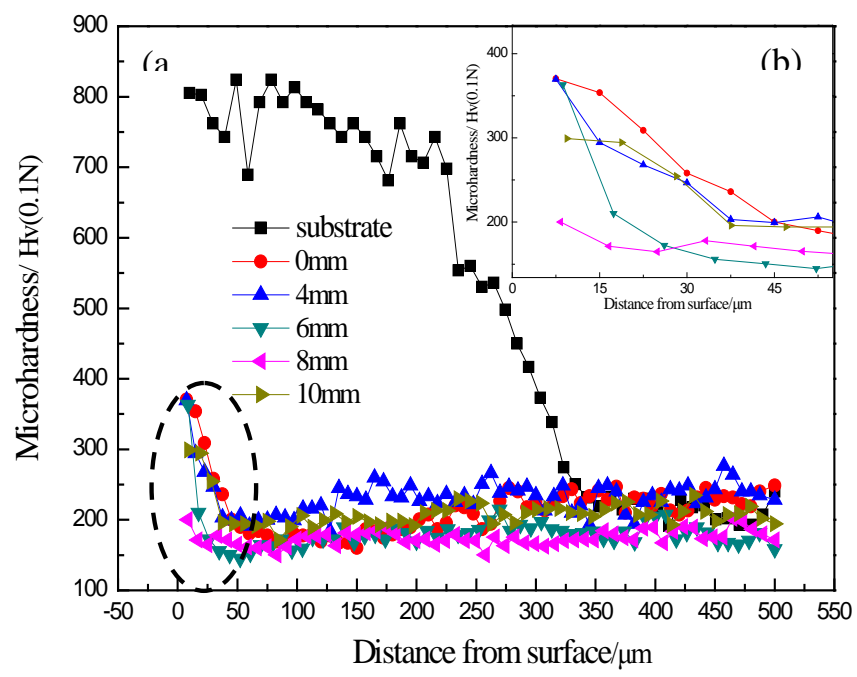

Fig.5 Microhardness of cross-section substract after carburizing under copper plating by mechanical attrition electroplating process at different diameter of glass ball (a) complete figure, (b) local figure with copper plating.

\section{Discussion}

It has been reported $[7,8]$ that scratch were detected on the surface of copper plating when the vibrator moved horizontally. In the electroplating process, the mechanical assisted electroplating device swinged with angle, most of glass balls were rolling on the surface of sample, and the friction is smaller than that of glass ball sliding on the surface of sample.

i) In actual electrode process, rate-determining step is a hybrid control about electron transfer an diffusion step[9]. It used stirring in the electroplating process that could enhance convection strength, reduce diffusion layer thickness and increase the limiting current density. High current density was used in the electroplating process, while the polarization degree increased and nucleation was promoted.

ii) Electroplating copper plating with MA process improves the adhesion of substrate and copper plating and reduces the porosity of plating. Under the compression and shearing load of glass balls, on one hand, copper plating mesh together with copper power ground down from copper plating because of displacement and deformation. On the other hand, the atoms on the surface of plating are close to each other, when the extranuclear electron of atom overlap with that of other atom, two copper atoms are welded together to form a new metallic bond[10,11]. It is obvious that the grains size of copper plating decreased while the diameter of glass ball increased. Hydrogen were prevented from adsorbing on the surface of cathode, and impurities were removed from surface to prevented from forming defects by using MA process in the electroplating process.

\section{Conclusions}

The conclusions are as follows:

i) MA action can affect electroplating process and lead to a finer surface morphology of the copper plating. The size of grains decrease as the diameters of glass ball increase from $0 \mathrm{~mm}$ to 8 mm.

ii) The porosity, corrosion resistance, carbon-impervious of plating first increase and then decrease with the diameter of glass balls increase from 0-10 $\mathrm{mm}$. 


\section{Acknowledgments}

We express our gratitude to the financial support of Jiangxi province education department (Grant No.DB201301052).

\section{References}

[1] Yu-Sheng Wang, Wen-Hsi Lee, Shih-Chieh Chang, et al. An electroplating method for copper plane twin boundary manufacturing. Thin Solid Films, 544, pp. 157-161,2013.

[2] N. R. Tao, Z. B. Wang, W.P. Tong, M. L.Sui, J. Lu, An investigation of surface nanocrystallization mechanism in Fe induced by surface mechanical attrition treatment. J. Acta Mater.50, pp. 4603,2002.

[3] M. Sato, N. Tsuji, Y. Minamino, Y. Koizumi, High Performance Structures and Materials. J. Sci. Technol. Adv.Mater.,5, pp. 145,2004.

[4] FENG Chang-jie, DU Nan, WANG Chun-xia, et al. Effects of Horizontally Vibrating Mechanical Attrition on the Microstructure of Electrodeposition $\mathrm{Cu}$ Coatings. Materials Engineering,6, pp. 81-86,2011.

[5] Zhaoxia Ping, Yedong He, Changdong Gu, et al. Mechanically assisted electroplating of Ni-P coatings on carbon steel. Surface \& Coatings Technology, 202, pp. 6023-6028,2008.

[6] Zhaoxia Ping, Yedong He, Guoan Cheng. Mechanical planarization of Ni-P electroless plating, Chinese jouranl of rare metals, 35, pp. 189-195,2011.

[7] Zhaohui Ning, Yedong He, W. Gao. Mechanical attrition enhanced Ni electroplating. Surface \& Coatings Technology, 202, pp. 2139-2146,2008.

[8] He Yedong, Fu Haifeng, Li xiaogang, et al. Microstructure and properties of mechanical attrition enhanced electroless Ni-P plating on magnesium alloy, 58, pp. 504,2008.

[9] Ning Zhao-hui, He Ye-dong. Rapid electroplating of copper coatings by mechanical attrition method. Transactions of Nonferrous Metals society of China, 18, pp. 1100-1106,2008.

[10] Leon L. Shaw, Jia-Wan Tian, Angel L. Ortiz, et al. A direct comparison in the fatigue resistance enhanced by surface severe plastic deformation and shot peening in a C-2000 superalloy. Materials Science and Engineering A, 527, pp. 986-994,2010.

[11] Yarilyn Cedeno-Mattei, Oscar Perales-Perez, Oswald N.C. Uwakweh. Effect of high-energy ball milling time on structural and magnetic properties of nanocrystalline cobalt ferrite powders. Journal of Magnetism and Magnetic Materials, 341, pp. 17-24,2013. 